\title{
Fatores de risco associados à prevalência de anticorpos anti-Sarcocystis neurona, Neospora spp. e Toxoplasma gondii em equinos de Roraima, Amazônia ${ }^{1}$
}

\author{
Kledir A.H. Spohr²,5 Alice M.C.M. Borges ${ }^{5}$, Taiã M.P. Ribeiro ${ }^{3}$, Valéria S. Jayme ${ }^{3}$, \\ Isabela Godoy ${ }^{4}$, Luciano Nakazato ${ }^{4}$, Valéria Dutra ${ }^{4}$ e Daniel M. Aguiar ${ }^{5 *}$
}

\begin{abstract}
Spohr K.A.H., Borges A.M.C.M., Ribeiro T.M.P., Jayme V.S., Godoy I., Nakazato L., Dutra V. \& Aguiar D.M. 2018. [Risk factors associated to the prevalence of anti-Sarcocystis neurona, Neospora spp. and Toxoplasma gondii antibodies in horses from Roraima, Brazilian Amazon.] Fatores de risco associados à prevalência de anticorpos anti-Sarcocystis neurona, Toxoplasma gondii e Neospora spp. em equinos de Roraima, Amazônia. Pesquisa Veterinária Brasileira 38(7):1337-1343. Laboratório de Virologia e Rickettsioses, Universidade Federal de Mato Grosso, Av. Fernando Corrêa da Costa 2367, Boa Esperança, Cuiabá, MT 78068600, Brazil. E-mail: danmoura@ufmt.br

Samples of 303 horses from 56 ranches of Rorainópolis municipality, state of Roraima, were evaluated by means of the Indirect Immunofluorescence Test (IFAT) to detect antibodies against Sarcocystis spp., Toxoplasma gondii and Neospora spp. A subset of positive sample (n=15) against Sarcocystis spp. was evaluated by Western Blotting (WB) with crude antigen of $S$. neurona. From the serological result, possible risk factors were evaluated against individual or farming variables. The prevalence of anti-Sarcocystis spp. antibodies was estimated to be $43.2 \%$ (37.6-49.0\%), anti-Neospora sp. was 26.7\% (21.9-32.2\%), and anti-T. gondii was 18.5\% (14.3-23.4\%). Fourteen samples $(14 / 15)$ evaluated by WB were positive for S. neurona antigens. From the ranches, $76.8 \%$ (43/56) presented at least one positive horse for Sarcocystis spp., 69.6\% (39/56) for Neospora spp., and 55.4\% (31/56) for T. gondii. Thirteen (14.3\%) horses had antibodies against all agents, $50(16.5 \%)$ had antibodies against Sarcocystis spp. and Neospora spp., 10 (3.3\%) for Neospora spp. and T. gondii, and eight (2.6\%) for Sarcocystis spp. and T. gondii. Associated variables ( $\mathrm{P} \leq 0.05)$ for antibodies against Neospora spp. were not found in horses fed on rented pastures, not in horses without veterinary assistance and stables, and not in herds up to 5 horses; while they were associated for T. gondii by contact with cats, in the Lavradeiro breed with use of stables, in horses raise with cattle, and in herds up to 5 horses. There were no variables associated with the presence of antibodies against $S$. neurona. Antibodies against $S$. neurona, Neospora spp. and T. gondii were reported in horses from the state of Roraima, Northern Brazilian Amazon, highlighting to the elevate prevalence on ranches.
\end{abstract}

INDEX TERMS: Risk factors, Sarcocystis neurona, Neospora spp., Toxoplasma gondii, antibodies, horses, Roraima, Amazon, immunofluorescence, Western Blotting, serology, epidemiology, parasitoses.

\footnotetext{
${ }^{1}$ Recebido em 29 de julho de 2017.

Aceito para publicação em 1 de setembro de 2017.

${ }^{2}$ Departamento de Medicina Veterinária, Universidade Federal de Roraima (UFRR), BR-174 Km 12, Bairro Monte Cristo, Boa Vista, RR 69300-000, Brasil. *Autor para correspondência: kledir.spohr@ufrr.br

${ }^{3}$ Laboratório de Diagnóstico de Leptospirose Animal, Universidade Federal de Goiás (UFG), Av. Esperança s/n, Campus Universitário, Goiânia, GO 74690900, Brasil.

${ }^{4}$ Laboratório de Microbiologia e Biologia Molecular Veterinária, Universidade Federal de Mato Grosso (UFMT), Av. Fernando Corrêa da Costa 2367, Boa Esperança, Cuiabá, MT 78068600, Brasil.

${ }^{5}$ Laboratório de Virologia e Rickettsioses, Universidade Federal de Mato Grosso (UFMT), Av. Fernando Corrêa da Costa 2367, Boa Esperança, Cuiabá, MT 78068600.
}

RESUMO.- Amostras de sangue de 303 equinos provenientes de 56 propriedades do município de Rorainópolis, Roraima, foram avaliadas por Reação de Imunofluorescência Indireta (RIF) para pesquisa de anticorpos contra Sarcocystis neurona, Toxoplasma gondii e Neospora spp. Algumas amostras de soros positivos para Sarcocystis spp. foram avaliadas pelo Western Blotting (WB) utilizando antígenos crus de S. neurona. A partir dos resultados sorológicos, possíveis fatores de risco foram avaliados frente a variáveis individuais e de propriedade. A prevalência de anticorpos anti-Sarcocystis spp. foi estimada em 43,2\% (37,6-49,0\%), anti-Neospora sp. em 
$26,7 \%(21,9-32,2 \%)$ e anti-T. gondii de 18,5\% (14,3-23,4\%). Quatorze amostras $(14 / 15)$ testadas por WB resultaram positivas para antígenos de $S$. neurona. Das propriedades, $76,8 \%(43 / 56)$ apresentaram pelo menos um equino positivo para Sarcocystis spp.; 69,6\% (39/56) para Neospora spp. e 55,4\% (31/56) para T. gondii. Dos equinos, $13(4,3 \%)$ apresentarem anticorpos para os três agentes, $50(16,5 \%)$ para Sarcocystis spp. e Neospora spp., 10 (3,3\%) para Neospora spp. e T. gondii, e oito $(2,6 \%)$ para Sarcocystis spp. e T. gondii. As variáveis associadas $(\mathrm{P} \leq 0,05)$ à presença de anticorpos foram: para Neospora spp. não pastejar em áreas alugadas, ausência de assistência veterinária na propriedade, sexo masculino, não estabular animais e plantel equino acima de 5 animais; enquanto para T. gondii foram o contato com felinos, animais da raça lavradeiro, animal estabulado, criação de bovinos na propriedade e plantel equino acima de 5 animais. Não houveram variáveis associadas a presença de anticorpos contra $S$. neurona. Relata-se no presente estudo a primeira detecção de anticorpos anti-S. neurona, Neospora spp. e T. gondii em equinos do estado de Roraima, localizado na Amazônia Setentrional Brasileira, ressaltando para a elevada frequência de fazendas com equinos soropositivos.

TERMOS DE INDEXAÇÃO: Fatores de risco, anti-Sarcocystis neurona, anti-Toxoplasma gondii, anti-Neospora spp., anticorpos, equinos, Roraima, Amazônia, imunofluorescência, Western Blotting, sorologia, epidemiologia, parasitoses.

\section{INTRODUÇÃO}

O equino no Brasil possui importante papel nas atividades de trabalho a campo, em especial na bovinocultura, além de exercer atividades de esporte e lazer (Brasil 2016). A ocorrência de enfermidades infecciosas ou infecto-parasitárias acarretam sérios prejuízos aos proprietários e animais, demandando gastos com diagnóstico, tratamento e manejo profilático, e eventualmente, geram sofrimento ao animal, com a ocorrência de doenças progressivas crônicas e que podem resultar em sequelas.

A mieloencefalite protozoária equina (EPM) se enquadra nestes casos. É uma doença causada pelo Sarcocystis neurona, um protozoário do Filo Apicomplexa, e caracterizada por anormalidades locomotoras dos membros posteriores, atrofia muscular e em alguns casos paralisia de nervos cranianos (Borges 2016). Quadros clínicos neurológicos em equinos também podem estar associados esporadicamente à infecção pelos protozoários Toxoplasma gondii e Neospora spp., especialmente N. hughesi (Dubey \& Su 2009, Marsh et al. 1996, Dubey \& Schares 2011). Os hospedeiros definitivos são gambas, felídeos e canídeos (Canis domesticus, C. latrans, C. lupus) respectivamente para $S$. neurona, T. gondii e Neospora spp. A transmissão em equinos ocorre basicamente pela ingestão de água ou alimentos contaminados com esporocistos de S. neurona e oocistos dos demais protozoários liberados pelas fezes dos hospedeiros definitivos (Dubey \& Su 2009, Dubey et al. 2015, Ribeiro et al. 2016).

As infecções por T. gondii, Neospora caninum e N. hughesi ainda podem estar associados a problemas reprodutivos no rebanho. Taxas de infecção em equinos variam entre estados, planteis e tipo de protozoário envolvido (Dubey \& Su 2009, Dubey \& Schares 2011). As infecções por T. gondii apresentam inclusive impacto na saúde pública como zoonose de interesse mundial (Dubey \& Su 2009).
Dados a respeito destas enfermidades no Brasil ainda são escassos, ou em algumas vezes inexistente, como na região norte do Brasil, em especial no estado de Roraima, localizado na Amazônia Setentrional Brasileira. Nestas regiões longínquas, o equino desempenha papel importante como fonte de trabalho e principalmente de transporte. Em Roraima, o município de Rorainópolis desponta como um importante polo de agricultura familiar. Este município está localizado na região sul do estado em território de aproximadamente 34 mil km² de bioma amazônico, onde predominam pequenas propriedades agrícolas oriundas de projetos federais de colonização. A agricultura é baseada em cultivos de rápido retorno e pecuária semi-extensiva (Roraima 2014).

Diante do exposto, o presente projeto objetivou estimar a prevalência de anticorpos contra S. neurona, Neospora spp. e T. gondii em equinos do município de Rorainópolis, buscando possíveis associações com a presença de animais soropositivos.

\section{MATERIAL E MÉTODOS}

O município de Rorainópolis $\left(00^{\circ} 56^{\prime} 45^{\prime \prime}\right.$ Norte e $60^{\circ} 25^{\prime} 04^{\prime \prime}$ Oeste) situa-se na região sul de Roraima, distante 290 quilômetros da capital Boa Vista (Fig.1). No município predomina o clima quente, com chuvas no verão e outono, temperatura média anual de $26^{\circ} \mathrm{C}$ e precipitação pluviométrica de $1.750 \mathrm{~mm}$. Na região nordeste do município o clima é equatorial com estação seca (Roraima 2014). Dados censitários de 2012 demonstram que a população de equinos no município foi estimada em 1426 animais (IBGE 2012). 0 número de equinos analisado foi calculado pelo programa EpiInfo 7.0 (CDC-Atlanta), considerando estimativa de prevalência de $50 \%$, erro de $5 \%$ e confiança de $95 \%$. Para compor o estudo, foram sorteadas propriedades presentes ao longo da BR-174 e estradas vicinais.

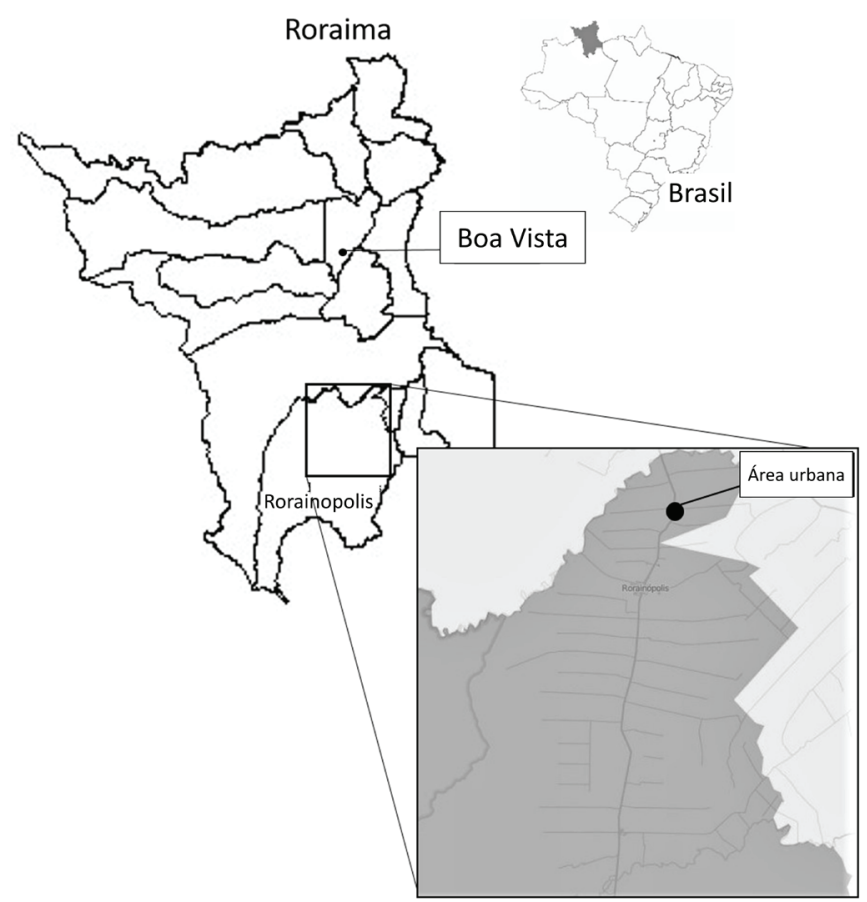

Fig.1. Mapa do município de Rorainópolis, Estado de Roraima, com destaque para a região nordeste ao logo da Rodovia BR-147 e vicinais onde foram realizadas as coletas de equinos. 
Certificamos que os procedimentos de amostragem estão de acordo com os Princípios Éticos na Experimentação Animal, adotado pelo Colégio Brasileiro de Experimentação (COBEA) e aprovado pelo Comitê de Ética no uso de Animais (CEUA-UFRR) sob o número de protocolo no. 04/2015.

As amostras de sangue foram coletadas entre 2013 e 2014 e os soros estocados em triplicata, em microtubos de poliestireno a $-20^{\circ} \mathrm{C}$. A pesquisa de anticorpos foi realizada por meio da Reação de Imunofluorescência Indireta (RIFI) utilizando como antígenos merozoítos da cepa SN37R de Sarcocystis. neurona (Duarte et al. 2003), taquizoítos da cepa NC1 de Neospora caninum (Villalobos et al. 2006) e RH de Toxoplasma gondii (Camargo 1974), todos produzidos em cultivos de células CV-1. As amostras foram triadas a 1:25, 1:50 e 1:16 respectivamente, sendo posteriormente diluídas na base dois até determinação da titulação final. Conjugado comercial anti-IgG equino produzido em coelhos (Sigma-Aldrich, USA) foi utilizado como anticorpo secundário nas diluições de 1:600, 1:800 e 1:900 para as reações anti-S. neurona, Neospora spp e T. gondii respectivamente. Controles positivos e negativos foram testados em cada uma das lâminas.

Com intuito de confirmar a positividade frente antígenos específicos de $S$. neurona, uma parcela de amostras positivas na RIFI foi submetida ao teste de Western Blotting (WB) utilizando antígenos brutos do respectivo agente conforme protocolos de Hoane et al. (2005). Considerou-se positivas as amostras que apresentaram reação contra a proteína imunodominante de 17-kDa.

Durante a coleta das amostras, foi aplicado um questionário epidemiológico para obter dados relativos a características individuais como sexo, faixa etária, raça, tipo de atividade, uso de estábulo, pastejo em áreas alugadas, assistência veterinária, contato com felinos, roedores, bovinos, suínos, animais silvestres. As propriedades foram caracterizadas segundo a exploração, o tipo e a zona de criação, tamanho do rebanho, topografia, fonte de água, pastejo em áreas alagadiças, transporte de equinos e vacinação. As variáveis foram avaliadas quanto a associação com a presença de animais soropositivos para os três diferentes agentes estudados, pelo teste de Chi-quadrado ( $\chi 2$ ) ou Teste Exato de Fisher's, e aquelas que apresentaram $\mathrm{p} \leq 0.05$ foram consideradas significativas. Para a análise foi utilizado o software estatístico EpiInfo 7.1.4 para Windows.

\section{RESULTADOS}

Foram coletados 303 equinos em 56 propriedades rurais. 0 tamanho médio do plantel de equinos variou de 01 a 28 animais, com média de 5,4 animais por propriedade. Dos animais coletados, $236(77,9 \%)$ eram adultos ( $>2$ anos) e $67(22,1 \%)$ jovens $(<2$ anos), $182(60,0 \%)$ eram machos e $121(40 \%)$ fêmeas. Quanto a raça $48(15,8 \%)$ eram Quarto de Milha, 42 (13,9\%) eram Lavradeiros, 35 (11,5\%) eram Andaluza e $178(58,7 \%)$ não apresentaram raça definida (SRD). Quanto ao contato com diferentes espécies, 295 (97,3\%) tinham contato com cães na propriedade; $249(82,1 \%)$ com felinos, 268 (88,4\%) com bovinos, 182 (60,0\%) com suínos; $68(22,4 \%)$ com ovinos e $280(92,4 \%)$ com animais silvestres. Duzentos e sessenta e três $(86,8 \%)$ eram usados para o trabalho e $40(13,2 \%)$ somente para laser; $241(80,0 \%)$ eram criados de forma extensiva enquanto $62(20,0 \%)$ eram estabulados, $260(85,8 \%)$ recebiam algum tipo de suplementação alimentar; e $109(36,0 \%)$ recebiam assistência veterinária.

Das propriedades avaliadas, $37(66,0 \%)$ apresentavam plantel equino com no máximo 5 animais, 20 (35,7\%) tinham como principal atividade a bovinocultura de corte,
$7(12,5 \%)$ bovinocultura de leite, $22(39,0 \%)$ bovinocultura mista e $7(12,5 \%)$ a equideocultura. Trinta e cinco $(62,5 \%)$ propriedades não realizavam qualquer tipo de vacinação no plantel, $10(17,8 \%)$ alugavam pastagens para alimentação dos animais; $39(70,0 \%)$ movimentavam os animais fora da propriedade e $34(61,0 \%)$ participavam de eventos. Eram utilizadas fontes de água provenientes de rio em $50(89,0 \%)$ fazendas, e em $47(84,0 \%)$ os animais pastejavam em áreas alagadiças.

A prevalência de anticorpos anti-Sarcocystis spp. foi estimada em 43,2\% (37,6-49,0\%), sendo detectados em 131 equinos, com títulos de 1:25 ( $\mathrm{n}=12), 1: 50$ (25), 1:100 (32), 1:200 (25), 1:400 (25); 1:800 (7); 1:1600 (3); 1:3200 (1); 1:6400 (1). Dos animais positivos para $S$. neurona, 15 amostras de diferentes títulos foram avaliadas por WB, e 14 apresentaram reação frente ao antígeno imunodominante de 17-kDa (Fig.2).

A prevalência estimada de anticorpos anti-Neospora spp. foi $26,7 \%(21,9-32,2 \%)$. Foram detectados em 81 animais as titulações de 1:50 (8), 1:100 (20), 1:200 (19), 1:400 (15), 1:800 (12), 1:1600 (5), 1:3200 (2). A prevalência estimada para T. gondii foi de $18,5 \%(14,3-23,4 \%)$. Anticorpos anti-T. gondii foram observados em 56 equinos e os títulos detectados foram 1:16 (5), 1:32 (7), 1:64 (10), 1:128 (21), 1:256 (9), 1:512 (2), $1: 1024$ (1), 1:2048 (1).

Das propriedades analisadas, 76,8\% (43/56) apresentaram pelo menos um animal positivo para Sarcocystis spp., 69,6\% (39/56) para Neospora spp. e 55,4\% (31/56) para T. gondii. Dos equinos, $13(4,3 \%)$ apresentarem anticorpos para os três agentes, 50 (16,5\%) para Sarcocystis spp. e Neospora spp., $10(3,3 \%)$ para Neospora spp. T. gondii, e oito $(2,6 \%)$ para Sarcocystis spp. e T. gondii. Embora todos os animais se apresentassem aparentemente saudáveis ao momento da coleta, somente $116(38,3 \%)$ equinos foram soronegativos frente a todos os protozoários testados. As variáveis relacionadas ao pastejo

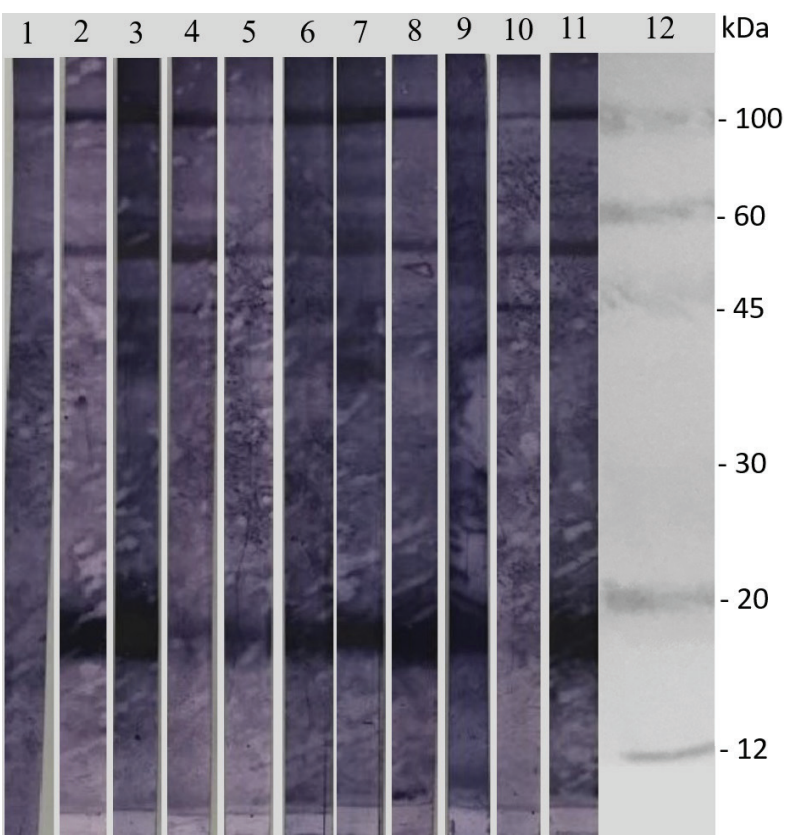

Fig.2. Amostras positivas para anti-Sarcocystis neurona (amostras 1-11) no teste de Western Blotting. Observa-se a intensa reatividade contra proteína imunodominante de 17-kDa (amostras 2-11). Considera-se negativa a amostra número 1. 
em áreas alugadas, assistência veterinária, uso de estábulo, sexo e tamanho de rebanho foram associados à Neospora spp., enquanto contato com felinos, raça lavradeiro, uso de estábulo, presença de bovinos e tamanho do plantel de equinos foram associados a T. gondii (Quadros 1 e 2). Nenhuma variável foi associada à presença de anticorpos anti-Sarcocystis spp.

Quadro 1. Associação entre variáveis individuais e soropositividade para Neospora spp. e Toxoplasma gondii, em equinos do município de Rorainópolis, Roraima

\begin{tabular}{|c|c|c|c|c|c|}
\hline \multirow{2}{*}{ Variável } & \multicolumn{2}{|c|}{ Testados } & \multicolumn{2}{|c|}{ Positivos } & \multirow{2}{*}{$P$} \\
\hline & $\mathrm{N}$ & $\%$ & $\mathrm{~N}$ & $\%$ & \\
\hline \multicolumn{6}{|l|}{ Neospora spp. } \\
\hline \multicolumn{6}{|c|}{ Pastejo em pastos alugados } \\
\hline Não & 246 & 81,2 & 75 & 30,5 & 0,002 \\
\hline Sim & 57 & 18,8 & 6 & 10,53 & \\
\hline \multicolumn{6}{|c|}{ Recebe assistência veterinária } \\
\hline Não & 194 & 64,0 & 59 & 30,4 & 0,05 \\
\hline Sim & 109 & 35,9 & 22 & 20,1 & \\
\hline \multicolumn{6}{|l|}{ Estabulado* } \\
\hline Não & 241 & 79,5 & 70 & 29,0 & 0,07 \\
\hline Sim & 62 & 20,4 & 11 & 17,7 & \\
\hline \multicolumn{6}{|l|}{ Sexo } \\
\hline Macho & 182 & 60,0 & 56 & 30,7 & 0,05 \\
\hline Fêmea & 121 & 29,9 & 25 & 20,6 & \\
\hline \multicolumn{6}{|l|}{ T. gondii } \\
\hline \multicolumn{6}{|l|}{ Contato com felinos } \\
\hline Não & 54 & 17,8 & 5 & 9,2 & 0,05 \\
\hline Sim & 249 & 82,1 & 51 & 20,4 & \\
\hline \multicolumn{6}{|l|}{ Lavradeiro } \\
\hline Não & 261 & 86,1 & 42 & 16,0 & 0,007 \\
\hline Sim & 42 & 13,8 & 14 & 33,3 & \\
\hline \multicolumn{6}{|l|}{ Estabulado* } \\
\hline Não & 241 & 79,5 & 39 & 16,1 & 0,04 \\
\hline Sim & 62 & 20,4 & 17 & 27,4 & \\
\hline
\end{tabular}

Quadro 2. Associação entre variáveis observadas nas propriedades e presença de foco para Neospora spp. e Toxoplasma gondii no município de Rorainópolis, Roraima

\begin{tabular}{|c|c|c|c|c|c|}
\hline \multirow{2}{*}{ Variável } & \multicolumn{2}{|c|}{ Avaliadas } & \multicolumn{2}{|c|}{ Positivas } & \multirow{2}{*}{$P$} \\
\hline & $\mathrm{N}$ & $\%$ & $\mathrm{~N}$ & $\%$ & \\
\hline \multicolumn{6}{|l|}{ Neospora spp. } \\
\hline \multicolumn{6}{|c|}{ Tamanho do plantel equino } \\
\hline$\leq 5$ animais & 37 & 66,0 & 21 & 56,7 & 0,004 \\
\hline$>5$ animais & 19 & 33,9 & 18 & 94,7 & \\
\hline \multicolumn{6}{|l|}{ Estabula os animais } \\
\hline Não & 47 & 83,9 & 23 & 48,9 & 0,03 \\
\hline Sim & 9 & 16,0 & 8 & 88,8 & \\
\hline \multicolumn{6}{|l|}{ T. gondii } \\
\hline \multicolumn{6}{|c|}{ Atividade de bovinocultura* } \\
\hline Não & 7 & 12,5 & 7 & 100,0 & 0,01 \\
\hline $\operatorname{Sim}$ & 49 & 87,5 & 24 & 48,9 & \\
\hline \multicolumn{6}{|c|}{ Tamanho do plantel equino } \\
\hline$\leq 5$ animais & 37 & 66,0 & 16 & 43,2 & 0,01 \\
\hline$>5$ animais & 19 & 33,9 & 15 & 78,9 & \\
\hline
\end{tabular}




\section{DISCUSSÃO}

0 presente trabalho avaliou pela primeira vez a presença de anticorpos contra três importantes protozoários para a espécie equina no estado de Roraima, Amazônia. Essa região apresenta características de colonização recente, ou de fronteira agrícola onde se concentram pequenas propriedades rurais com atividades de bovinocultura extensiva, com poucos equinos, de raça local ou de pouco valor zootécnico, na maioria machos adultos utilizados para serviço. A maioria das fazendas apresentava manejo sanitário deficiente, o que pode ser evidenciado pela baixa frequência de assistência médica veterinária e baixos índices vacinais, indicando pouco acesso a profissionais na região. 0 perfil dos dados apresentados demonstra claramente o papel e uso dos equinos nas atividades agropecuárias da região, além do que, a interação ou contato destes com diferentes espécies animais, sobretudo felinos, cães, e fauna silvestre observados nas propriedades deste estudo. Diferentes trabalhos indicam que o contato com diferentes fontes de infecção favorece a transmissão de enfermidades parasitárias (Dubey et al. 2015).

Aproximadamente $40 \%$ da população equina do município apresentou anticorpos anti-Sarcocystis spp., inclusive uma parcela destes soropositivos reagiram fortemente aos antígenos de $S$. neurona quando testados por ensaio Western Blotting, confirmando tratar-se de anticorpos específicos para o agente. Segundo a literatura consultada, os resultados do presente estudo embora com valores abaixo do observado em outras regiões (Hoane et al., 2006), são expressivos, pois frequências relatadas por outros autores no Brasil estão em torno de 25-30\% (Lins et al. 2012, Ribeiro et al. 2016). Embora os animais avaliados se apresentassem sadios, há relatos informais na região de casos clínicos de equinos que vieram a óbito com sinais neurológicos, porém negativos para o vírus da raiva (informação pessoal). Diante da alta ocorrência de soropositivos, deve-se incluir como diagnóstico diferencial em casos não confirmados de raiva, a infecção por $S$. neurona. Nenhuma variável apresentou-se associada à presença de equinos soropositivos e pelo menos $76 \%$ das fazendas apresentam pelo menos um animal soro reagente, sugerindo que o agente encontra-se disseminado na região.

A prevalência estimada de equinos com anticorpos anti-Neospora spp. na região assemelha-se as frequências observadas em outros locais, como no Rio Grande de Sul (Sangioni et al. 2011), Paraná (Villalobos et al. 2012), Mato Grosso (Laskoski et al. 2015) e Minas Gerais (Ribeiro et al. 2016). Embora se tenha utilizado antígenos de Neospora caninum, não é possível determinar a provável espécie envolvida devido a reatividade cruzada ocasionada por $N$. hughesi (Marsh et al. 1998, Gondim et al. 2009). No Brasil, além de não haver registros oficiais de infecção por N. hughesi, Borges et al. (2017) relataram maior reatividade a antígenos brutos de $N$. caninum por WB do que quando utilizado antígenos de N. hughesi.

Foi observado no presente estudo associação entre a soropositividade para Neospora spp. e o não pastejo em pastagens alugadas. As áreas alugadas para pastagem nesta região geralmente não são habitadas, subtendendo-se que não há cães domésticos habitando nesses locais. Este resultado sugere que a infecção e a consequente soroconversão esteja ocorrendo na propriedade de origem dos equinos, nas proximidades da habitação, onde é favorecido o contato em áreas coabitadas com cães. Cães domésticos e selvagens são hospedeiros definitivos de N. caninum (McAllister et al. 1998, Gondim et al. 2004). Por outro lado, não foi observado associação entre a presença de cães na propriedade com a presença de cavalos positivos para Neospora spp., fato que pode ser justificado pelo grande número de propriedades (96\%) que apresentavam cães. Adicionalmente, observou-se associação com a positividade em equinos machos e ausência de assistência veterinária. 0 hábito de não estabular equinos apresentou tendência a presença de anticorpos nos animais. Estes resultados reforçam a ocorrência de transmissão horizontal, pois sugerem que equinos que permanecem a pasto estão mais expostos ao agente, os animais machos compõe a categoria mais utilizada em trabalho extensivo, bem como a ausencia de assistência veterinária denota a falta de manejo sanitário orientado por profissional.

A prevalência de anticorpos anti-Toxoplasma gondii foi estimada ao redor de $18,5 \%$ e este resultado assemelha-se a vários estudos realizados no Brasil, bem como em outros países (Vidotto et al. 1997, Dubey et al. 1999, Dangoudoubiyam et al. 2011, Garcia-Bocanegra et al. 2012, Evers et al. 2013, Finger et al. 2013, Gennari et al. 2015, Ribeiro et al. 2016). Diferenças nas taxas de positividade podem estar associadas a utilização de diferentes técnicas de diagnóstico, diferenças locais de manejo, bem como tipo de plantel estudado. Assim como em outros estudos (Dubey et al. 2003, Ribeiro et al. 2016), a frequência de propriedades com equinos soropositivos para T. gondii foi inferior do que para Sarcocystis neurona e Neospora spp. e este resultado pode estar associado a transmissão horizontal, principalmente pela presença de diferentes hospedeiros definitivos nos locais.

A ocorrência de anticorpos anti-T. gondii foi associado a presença de gatos e a prática de estabular animais. Ambas variáveis influenciam a exposição de equinos com oocistos eliminados nas fezes dos gatos, por meio da contaminação de alimentos ou águas. A prevalência de anticorpos anti-T. gondii foi também associada à raça local, designada "lavradeiro". Tradicionalmente esses animais são asselvajados vivendo nas savanas locais e são capturados e domados para o trabalho (Braga 2005). Embora os cavalos lavradeiros testados no presente estudo eram todos domados, esta variável, pode indicar uma maior exposição destes animais ao agente, sobretudo por frequentarem antes da captura, ambientes pouco antropotizados. Assim como para Neospora spp., propriedades com mais de cinco equinos foram associadas a presença de animais positivos para T. gondii. A aglomeração de animais poderia facilitar o contato entre animais e oocistos presentes no meio ambiente.

0 presente estudo relata pela primeira vez a detecção de anticorpos anti-S. neurona e Neospora spp. em equinos do estado de Roraima, com elevada frequência de propriedades com equinos soropositivos. A análise de fatores de risco demonstra que a presença de animais positivos está provavelmente relacionada à transmissão horizontal, caracterizada pela presença de animais considerados hospedeiros definitivos no local e a contaminação do ambiente. Manejos diferenciados como a estabulação e a criação totalmente extensiva, estão associados a ocorrência de soropositividade para T. gondii e Neospora spp., respectivamente, demonstrando cadeias de transmissão distintas. De acordo com os resultados do presente estudo, as medidas de prevenção devem ser baseadas no 
controle de animais reservatórios para os agentes estudados bem como calcadas nas formas de disseminação entre animais susceptíveis.

Agradecimentos.- À Universidade Federal de Roraima (UFRR) pelo apoio logístico. À Fundação de Amparo à Pesquisa do Estado do Mato Grosso (FAPEMAT processo 212827/2015) pelo apoio no desenvolvimento desta pesquisa, à Coordenação de Aperfeiçoamento de Pessoal de Nível Superior (CAPES) pela bolsa de estudo concedida à A.M.C.M. Borges e I. de Godoy, e ao Conselho Nacional de Desenvolvimento Científico e Tecnológico (CNPq) pela Bolsa de Produtividade Científica concedida à L. Nakazato, V. Dutra e D.M Aguiar.

\section{REFERÊNCIAS}

Borges A.S. 2016. Mieloencefalite protozoária equina, p.1025-1031. In: Medig J., Ribeiro M.G. \& Paes A.C. (Eds), Doenças Infecciosas em Animais de Produção e de Companhia. Roca, Rio de Janeiro.

Borges A.M.C., Yeargan M.R., Silva L.G., Taques I.I.G.G., Howe D. \& Aguiar D.M. 2017. Antibodies against Sarcocystis neurona, Neospora spp., and Toxoplasma gondii in horses and mules from the Northern Pantanal Wetland of Brazil. J. Equine Vet. Sci. 56:19-25.<http://dx.doi.org/10.1016/j.jevs.2017.04.007>

Braga R.M. 2005. Animais domésticos nas savanas (bovinos, ovinos e equinos), p.183-193. In: Barbosa R.I., Xaud H.A.M., Costa e Souza J.M. (Eds), Savanas de Roraima: etnoecologia, biodiversidade e potencialidades agrossilvipastoris. FEMACT, Boa Vista.

Brasil 2016. Ministério da Agricultura, Pecuária e Abastecimento. Disponível em < <http://www.agricultura.gov.br/animal/especies/equideos $>$ Acesso em 10 set. 2016 .

Camargo M.E. 1974. Introdução as técnicas de imunofluorescência. Revta Bras. Patol. Clin. 10(3):87-107.

Dangoudoubiyam S., Oliveira J.B., Víquez C., Gómez-García A., González O., Romero J.J., Kwok O.C.H., Dubey J.P. \& Howe D.K. 2011. Detection of antibodies against Sarcocystis neurona, Neospora spp., and Toxoplasma gondii in horses from Costa Rica. J. Parasitol. 97(3):522-524. <http:// dx.doi.org/10.1645/GE-2722.1> <PMid:21506839>

Duarte P.C., Daft B.M., Conrad P.A., Packham A.E. \& Gardner I.A. 2003. Comparision of a serum indirect fluorescent antibody test with two western blots tests for the diagnosis of equine protozoal myeloencephalits. J. Vet. Diagn. Invest. 25(1):8-13.<http://dx.doi.org/10.1177/104063870301500103> <PMid:12580288>

Dubey J.P. \& Su C. 2009. Population biology of Toxoplasma gondii: what's out and where did they come from. Mem. Inst. Oswaldo Cruz 104(2):190-195. <http://dx.doi.org/10.1590/S0074-02762009000200011><PMid:19430643>

Dubey J.P. \& Schares G. 2011. Neosporosis in animals: the last five years. Vet. Parasitol. 180(1/2):90-108. <http://dx.doi.org/10.1016/j.vetpar.2011.05.031> <PMid:21704458>

Dubey J.P., Venturini M.C., Venturini L., McKinney J. \& Pecoraro M. 1999. Prevalence of antibodies to Sarcocystis neurona, Toxoplasma gondii and Neospora caninum in horses of Argentina. Vet. Parasitol. 86(1):59-62. <http://dx.doi.org/10.1016/S0304-4017(99)00127-2><PMid:10489203>

Dubey J.P., Howe D.B., Furr M., Saville W.J., Marsh A.E., Reed S.M. \& Grigg M.E. 2015. An update on Sarcocystis neurona infections in animals and equine protozoal myeloencephalitis (EPM).Vet. Parasitol. 209(1/2):1-42. <http:// dx.doi.org/10.1016/j.vetpar.2015.01.026> <PMid:25737052>

Dubey J.P., Mitchell S.M., Morrow J.K., Rhyan J.C., Stewart L.M., Granstrom D.E., Romand S., Thulliez P., Saville W.J. \& Lindsay D.S. 2003. Prevalence of antibodies to Neospora caninum, Sarcocystis neurona, and Toxoplasma gondii in wild horses from Central Wyoming. J. Parasitol. 89(4):716-720. <http://dx.doi.org/10.1645/GE-66R> <PMid:14533680>

Evers F., Garcia J.L., Navarro I.T., Zulpo D.L., Nino B.S.L., Ewald M.P.C., Pagliari S., Almeida J.C. \& Freire R.L. 2013. Diagnosis and isolation of Toxoplasma gondii in horses from Brazilia slaughterhouses. Braz. J. Vet. Parasitol.
22(1):58-63.<http://dx.doi.org/10.1590/S1984-29612013005000009> $<$ PMid:23538498>

Finger M.A., Villalobos E.M.C., Lara M.C.C.S.H., Cunha E.M.S., Barros Filho I.R., Deconto I., Dornbusch P.T., Ullmann L.S. \& Biondo A.W. 2013. Detection of anti-Toxoplasma gondii antibodies in carthorses in the metropolitan region of Curitiba, Paraná, Brazil. Braz. J. Vet. Parasitol. 22(1):179-181.<http:// dx.doi.org/10.1590/S1984-29612013005000001> <PMid:23459849>

García-Bocanegra I., Cabezón O., Arenas-Montes A., Carbonero A., Dubey J.P., Perea A. \& Almeria S. 2012. Seroprevalence of Toxoplasma gondii in equids from southern Spain. Parasitol. Int. 61(3):421-424. <http://dx.doi. org/10.1016/j.parint.2012.02.003 > <PMid:22366344>

Gennari S.M., Esmerini P.O., Lopes M.G., Soares H.S., Vitaliano S.N., Cabral A.D., Pena H.F.J., Horta M.C., Cavalcante P.H., Fortes K.P. \& Villalobos E.M.C. 2015. Occurence of antibodies against Toxoplasma gondii and its isolation and genotyping in donkeys, mules, and horses in Brazil. Vet. Parasitol. 209(1/2):129-132. <http://dx.doi.org/10.1016/j.vetpar.2015.01.023> $<$ PMid:25747488>

Gondim L.F.P., Lindsay D.S. \& McAllister M.M. 2009. Canine and bovine Neospora caninum control sera examined for cross-reactivity using Neospora caninum and Neospora hughesi indirect fluorescent antibody tests. J. Parasitol. 95(1):86-88. <http://dx.doi.org/10.1645/GE-1710.1> <PMid:18613752>

Gondim L.F.P., McAllister M.M., Pitt W.C. \& Zemlicka D.E. 2004. Coyotes (Canis latrans) are definite hosts of Neospora caninum. Int. J. Parasitol. 34(2):159161. <http://dx.doi.org/10.1016/j.ijpara.2004.01.001><PMid:15037103>

Hoane J.S., Morrow J.K., Saville W.J., Dubey J.P., Granstrom D.E. \& Howe D.K. 2005. Enzyme-Linked Imunossorbent Assays for detection of equine antibodies specific to Sarcocystis neurona surface antigens. Clin. Diagn. Lab. Immunol. 12(9):1050-1056. <PMid:16148170>

Hoane J.S., Gennari S.M., Dubey J.P., Ribeiro M.G., Borges A.S., Yai L.E.O., Aguiar D.M., Cavalcante G.T., Bonesi G.L. \& Howe D.K. 2006. Prevalence of Sarcocystis neurona and Neospora spp. infection in horses from Brazil based on presence of serum antibodies to parasite surface antigen. Vet. Parasitol. 136(2):155-159. <http://dx.doi.org/10.1016/j.vetpar.2005.10.023> <PMid:16310955>

Ibge 2012. Censo Agropecuário 2012. Instituto Brasileiro de Geografia e Estatística. Disponível em <http://goo.gl/EdjbzF.> Acesso em 15 jan. 2015.

Laskoski L.M., Muraro L.S., Dittrich R.L., Abreu R.A., Koch M.O., Silva F.T. \& Hagi R.H. 2015. Ocorrência de anticorpos anti-Neospora caninum e antiToxoplasma gondii em equinos do Pantanal Mato-Grossense, Brasil. Semina, Ciênc. Agrárias 36(2):895-900.

Lins L.A., Feijó L.S. \& Nogueira C.E.W. 2012. Mieloencefalite protozoária equina nas regiões de Campanha e do sul do Rio Grande do Sul no período de 1998-2006. Revta Ciênc. Agrovet. 11(3):248-250.

Marsh A.E., Barr B.C., Packham A.E. \& Conrad P.A. 1998. Description of a new Neospora species (Protozoa: Apicomplexa: Sarcocystidae). J. Parasitol. 84(5):983-991. <http://dx.doi.org/10.2307/3284632><PMid:9794642>

Marsh A.E., Barr B.C., Madigan J., Lakritz J., Nordhausen R. \& Conrad P.A. 1996. Neosporosis as a cause of equine protozoal myeloencephalitis. J. Am. Vet. Med. Assoc. 209(11):1907-1913.<PMid:8944807>

McAllister M.M., Dubey J.P., Lindsay D.S., Jolley W.R., Wills R.A. \& McGuire A.M. 1998. Dogs are definitive hosts of Neospora caninum. Int. J. Parasitol. 28(9):1473-1478. <http://dx.doi.org/10.1016/S0020-7519(98)00138-6> <PMid:9770635>

Ribeiro M.J.M., Rosa M.H.F., Bruhn R.P., Garcia A.M., Rocha C.M.B.M. \& Guimarães A.M. 2016. Seroepidemiology of Sarcocystis neurona, Toxoplasma gondii and Neospora spp. among horses in the south of the state of Minas Gerais, Brazil. Braz. J. Vet. Parasitol. 25(2):142-150.<http://dx.doi.org/10.1590/ S1984-29612016029><PMid:27334814>

Roraima 2014. Secretaria de Estado do Planejamento e Desenvolvimento de Roraima (SEPLAN). Informações socioeconômicas do município de 
Rorainópolis, RR. $4^{\mathrm{a}}$ ed. DIEP, Boa Vista/RR. Disponível em < file:///C:/Users/ ufrr/Downloads/Informac\%CC\%A7o\%CC\%83es\%20socioeconomicas $\% 20$ do\%20municipio\%20de\%20Roraino\%CC\%81polis\%20(2).pdf> Acesso em 28 mai. 2017.

Sangioni L.A., Botton A.V., Cargnelutti J.P., Cadore G.C., Cezar A.S., Weiblen R., Lopes S.T.A. \& Vogel F.S.F. 2011. Looking for antibodies anti-Neospora spp. and anti-equine herpesvirus in carter horses in Santa Maria, Brazil. Ciência Rural 41(2):321-323. <http://dx.doi.org/10.1590/S010384782011000200023>

Vidotto O., Kano F.S., Freire R.L., Mitsuka O.L., Ogawa L., Bonesi G., Navaroo I.T. \& Franciscon F.S.G. 1997. Ocorrência de anticorpos anti-Toxoplasma gondii em equinos procedentes de quatro estados (SP, PR, MS e MT) abatidos em Apucarana, PR. Semina, Ciênc. Agrárias 18(1):9-13.

Villalobos E.M.C., Ueno T.E.H., Souza S.L.P., Cunha E.M.S., Lara M.C.C.S.H., Gennari S.M. \& Soares R.M. 2006. Association between the presence of serum antibodies against Neospora spp. and fetal loss in equines. Vet. Parasitol. 142(3/4):372-375. <http://dx.doi.org/10.1016/j.vetpar.2006.07.016> $<$ PMid:16962708>

Villalobos E.M.C., Furman K.E., Lara M.C.C.S.H., Cunha E.M.S., Finger M.A., Busch A.P.B., Barros Filho I.R., Deconto I., Dornbusch P.T. \& Biondo A.W. 2012. Detection of Neospora sp. antibodies in cart horses from urban areas of Curitiba, southern Brazil. Revta Bras. Parasitol. Vet. 21(1):68-70.<http:// dx.doi.org/10.1590/S1984-29612012000100014><PMid:22534949> 